\title{
Infestação de Anthonomus grandis (Coleoptera: Curculionidae) em rebrota de algodoeiro ${ }^{1}$
}

\author{
José Fernando Jurca Grigolli2, Jacob Crosariol Netto ${ }^{3}$, \\ Tiago Sabongi Izeppi ${ }^{3}$, Leandro Aparecido de Souza ${ }^{3}$, Diego Felisbino Fraga ${ }^{3}$, Antonio Carlos Busoli ${ }^{3}$
}

\begin{abstract}
Infestation of Anthonomus grandis (Coleoptera:

Curculionidae) on re-sprout of cotton plants

The destruction of cotton crop residues at the end of the crop cycle is a key strategy for the phytosanitary crop management, since its off-season re-sprout can provide sites for feeding and oviposition of pests such as the boll weevil. This study aimed to evaluate the re-sprout capacity of cotton cultivars, as well as their infestation by Anthonomus grandis. A randomized blocks design, in a $3 \times 2$ factorial arrangement, with three cultivars (FM 910, DeltaOPAL and NuOPAL), two mowing heights $(10 \mathrm{~cm}$ and $20 \mathrm{~cm})$ and four replications, was used. Weekly evaluations were carried out for measuring the percentage of plant re-sprout for both mowing heights, percentage of flower buds infested by the boll weevil and number of adults per re-sprout. Plants mowed at $10 \mathrm{~cm}$ presented a lower sprout capacity and consequently less flower buds, reducing the boll weevil population density in the area, while plants mowed at $20 \mathrm{~cm}$ showed high re-sprouts rates, seven days after mowing. The FM 910 cultivar had the highest number of re-sprout plants, while the DeltaOPAL cultivar showed the highest number of flower buds and adults per plant, as well as the highest percentage of buds damaged by the boll weevil.
\end{abstract}

KEY-WORDS: Gossypium hirsutum; boll weevil; cotton stalk.

\section{INTRODUÇÃO}

O algodoeiro (Gossypium hirsutum L.) é uma planta perene, que pode permanecer por vários anos em ambientes favoráveis. A natureza perene do algodoeiro permite sua rebrota após a colheita, produzindo estruturas adequadas à reprodução e manutenção do bicudo-do-algodoeiro (Anthonomus grandis Boheman, 1843) (Coleoptera: Curculionidae), na área de cultivo, após três ou quatro semanas (Greenberg et

\section{RESUMO}

A destruição dos restos culturais do algodoeiro, ao final do ciclo de cultivo, é uma estratégia fundamental no manejo fitossanitário da cultura, já que a sua rebrota, no período de entressafra, pode oferecer sítios de alimentação e de oviposição para pragas como o bicudo-do-algodoeiro. Este trabalho objetivou avaliar a capacidade de rebrota de cultivares de algodoeiro, bem como sua infestação por Anthonomus grandis. Utilizou-se o delineamento experimental em blocos casualizados, em esquema fatorial $3 \times 2$, com três cultivares (FM 910, DeltaOPAL e NuOPAL), duas alturas de roçagem $(10 \mathrm{~cm}$ e $20 \mathrm{~cm})$ e quatro repetições. Foram realizadas avaliações semanais da porcentagem de rebrota das plantas nas duas alturas de roçagem, número de botões florais, porcentagem de botões florais infestados pelo bicudo e número de adultos por rebrota. Plantas roçadas a $10 \mathrm{~cm}$ de altura apresentaram menor capacidade de brotação e, consequentemente, de emissão de botões florais, reduzindo a densidade populacional do bicudo na área, enquanto plantas roçadas a $20 \mathrm{~cm}$ apresentaram altos índices de rebrota, aos sete dias após a roçada. A cultivar FM 910 apresentou o maior número de plantas rebrotadas e, para a cultivar DeltaOPAL, registrou-se o maior número de botões florais e adultos por planta, bem como a maior porcentagem de botões com danos causados pelo bicudo-do-algodoeiro.

PALAVRAS-CHAVE: Gossypium hirsutum; bicudo-doalgodoeiro; soqueira de algodão.

al. 2007a). Segundo esses autores, o potencial de rebrota do algodoeiro, em regiões temperadas, é pouco prejudicial, devido à morte das plantas e redução das populações de bicudo-do-algodoeiro, mas em regiões tropicais e subtropicais, esse crescimento vegetativo do algodoeiro pode dificultar o manejo dessa praga, pelo cotonicultor.

O bicudo-do-algodoeiro é uma praga de grande importância para a cotonicultura, ocasionando sérios danos aos campos de produção, desde o cinturão do

1. Trabalho recebido em out./2014 e aceito para publicação em mai./2015 (http://dx.doi.org/10.1590/1983-40632015v4532296).

2. Fundação MS para Pesquisa e Difusão de Tecnologias Agropecuárias, Maracaju, MS, Brasil. E-mail: fernando@fundacaoms.org.br.

3. Universidade Estadual Paulista (Unesp), Faculdade de Ciências Agrárias e Veterinárias, Departamento de Fitossanidade, Jaboticabal, SP, Brasil.E-mails: jacob_netto@hotmail.com, tizeppi@yahoo.com.br, leandroagronomia@hotmail.com, diegoffraga@hotmail.com, acbusoli@fcav.unesp.br. 
algodão, nos EUA, até a Argentina (Ramalho \& Jesus 1988, Cuadrado 2002, Ribeiro et al. 2010). Uma das estratégias de manejo do bicudo é a destruição dos restos culturais e o vazio sanitário, que auxiliam na redução de populações dessa praga, ao final do ciclo de cultivo.

A destruição das soqueiras do algodoeiro é uma prática de cultivo obrigatória no Brasil (Brasil 1993a, 1993b e 1994). Essa prática é bastante eficiente e de rápida execução em pequenas áreas, mas, em grandes áreas, o tempo necessário para realizar tal operação é prolongado, o que possibilita o aparecimento e o desenvolvimento de insetos-pragas, que atacam as estruturas vegetais dessas rebrotas do algodoeiro (Greenberg et al. 2007a).

A rebrota pode favorecer o aumento populacional dessas pragas no cultivo subsequente e, assim, ocasionar prejuízos severos ao agricultor (Walker 1986, Greenberg et al. 2007a). Por essa razão, o aprimoramento dessa prática da roçagem do algodoeiro, para grandes áreas, pode ser de grande importância para o cotonicultor.

Este trabalho objetivou avaliar a capacidade de rebrota de três cultivares de algodoeiro, em duas alturas de roçagem, bem como a infestação de A. grandis, no período de entressafra.

\section{MATERIAL E MÉTODOS}

O estudo foi realizado em área experimental da Faculdade de Ciências Agrárias e Veterinárias da Universidade Estadual Paulista (Unesp), em Jaboticabal (SP), de novembro de 2010 a agosto de 2011.

O delineamento experimental adotado foi em blocos casualizados, em esquema fatorial $3 \times 2$ (cultivares $\mathrm{x}$ alturas de roçagem), com quatro repetições. A área do experimento foi de $3.500 \mathrm{~m}^{2}$, sendo dividida em duas partes iguais. A primeira área experimental foi roçada a $10 \mathrm{~cm}$ de altura e a segunda a $20 \mathrm{~cm}$ de altura. Como os experimentos com alturas de roçagem diferentes foram conduzidos na mesma época e lado a lado, na mesma área experimental, os resultados foram comparados entre si.

As cultivares utilizadas foram FM 910, DeltaOPAL e a sua isolinha transgênica NuOPAL (Bollgard $\mathrm{I}^{\circledR}$ ), todas de grande importância econômica, devido ao cultivo em larga escala, em áreas produtoras de algodoeiro no Brasil.

Cada parcela foi constituída por oito linhas de plantas, com 20,0 m de comprimento e linhas espa- çadas em 0,9 m. Como área útil das parcelas, foram consideradas as seis linhas centrais, eliminando-se 1,0 m em cada extremidade da linha.

O solo foi preparado e corrigido com uma aração seguida de duas gradagens, tendo-se por finalidade a eliminação de torrões, uniformização do terreno e nivelamento do solo, além da eliminação de sementeiras de plantas daninhas, para posterior realização da semeadura.

A adubação de plantio foi realizada com $250 \mathrm{~kg} \mathrm{ha}^{-1}$ de NPK 08-20-20 e a adubação de cobertura aos 30 dias após a emergência das plantas (DAE), com $150 \mathrm{~kg} \mathrm{ha}^{-1}$ de sulfato de amônio.

A semeadura do algodão (Gossypium hirsutim) foi realizada manualmente, em 19 de novembro de 2010, com densidade média de 14 plantas por metro de linha. A emergência das plantas ocorreu em 27 de novembro de 2010 e, sete dias após a emergência, foi realizado o desbaste, mantendo-se densidade média de dez plantas por metro de linha.

Durante o desenvolvimento das plantas, não foi utilizado nenhum inseticida para o controle de pragas. Aos 45 DAE, 60 DAE e 70 DAE, foi aplicado o regulador de crescimento cloreto de mepiquat (Pix), nas dosagens de 0,25 Li.a. ha-1, 0,10 L i.a. ha ${ }^{-1}$ e 0,10 L i.a. ha-1 . Aos 60 DAE, 70 DAE e 80 DAE, foram utilizados fungicidas à base de benzimidazol e triazol, na dosagem de 0,8 L i.a. ha ${ }^{-1}$, para evitar a ocorrência de ramulose e ramulária.

As plantas daninhas foram controladas manualmente, quando necessário. Aos 160 DAE, foi realizada a roçagem das plantas, em duas alturas $(10 \mathrm{~cm}$ e $20 \mathrm{~cm})$, com o auxílio de uma roçadeira hidráulica, com duas facas de altura regulável, acoplada ao sistema hidráulico do trator.

Após a roçagem, foram realizadas avaliações semanais nas plantas de algodoeiro, até os 91 dias após a roçagem (DAR). Para isso, foram contadas as plantas presentes em 1,0 $\mathrm{m}$ de linha, tomado ao acaso na parcela, registrando-se os seguintes parâmetros: porcentagem de plantas rebrotadas, número de botões florais, porcentagem de botões florais que apresentaram orifícios de alimentação e de oviposicão do bicudo-do-algodoeiro e número de adultos nas rebrotas.

As avaliações dos parâmetros de rebrota dos restos culturais foram realizadas semanalmente, dos 7 DAR aos 56 DAR. Foi considerada planta rebrotada aquela que apresentou pelo menos uma folha aberta. As avaliações baseadas na presença de adultos por 
planta rebrotada e no número de botões florais utilizados para alimentação e oviposição do bicudo-do-algodoeiro foram iniciadas aos 56 DAR, quando as plantas já apresentavam os primeiros botões florais com danos de alimentação, e se estenderam até os 91 DAR.

Além disso, foi colocada uma armadilha de feromônio sexual para bicudo-do-algodoeiro, na área, para monitoramento da população da praga ao longo do período de avaliação. O feromônio utilizado foi o Luretape BW10 ${ }^{\circledR}$ (Grandlure), da Biocontrole (São Paulo, SP, Brasil). A cápsula emissora do feromônio foi trocada a cada 21 dias e a armadilha vistoriada semanalmente, nas datas de avaliação, registrando-se o número de adultos capturados por semana.

Os dados obtidos foram submetidos à análise de variância (Anova) e as médias dos tratamentos comparadas pelo teste Tukey, a $5 \%$. As análises estatísticas foram realizadas por meio do programa AgroEstat versão 1.0 (Barbosa \& Maldonado Júnior 2010).

Para atender às pressuposições de normalidade da Anova, os dados obtidos de porcentagem de plantas rebrotadas e de botões florais que apresentaram orifícios de alimentação foram transformados em arcsen $V_{\mathrm{X}} / 100$. Os dados para número de botões florais com orifícios de alimentação do bicudo-do-algodoeiro e de insetos adultos encontrados nas plantas foram transformados em $\sqrt{ } \mathrm{x}+0,5$.

\section{RESULTADOS E DISCUSSÃO}

A capacidade de rebrota das cultivares, em função da altura de roçagem das plantas de algodoei- ro, apresentou diferenças significativas. Os valores observados foram superiores a $40 \%$, nas cultivares FM 910 e NuOPAL, já aos 7 DAR, aumentando até o final das avaliações. Aos 56 DAR, o maior percentual de rebrota foi observado na cultivar FM 910, seguida pela DeltaOPAL e NuOPAL.

As porcentagens médias de plantas de algodão rebrotadas, nas três primeiras avaliações (7 DAR, 14 DAR e 21 DAR), não apresentaram interação significativa entre cultivares e altura de roçagem, indicando que a rebrota das plantas após a roçagem não está ligada à altura de roçagem das plantas. No entanto, observou-se interação significativa entre esses fatores dos 28 DAR aos 56 DAR, indicando que a altura de roçagem influencia significativamente nas diferenças de porcentagem de rebrota entre as cultivares, a médio prazo.

As porcentagens médias de plantas rebrotadas durante todo o período de avaliação diferiram entre as alturas de roçagem de $10 \mathrm{~cm}$ e $20 \mathrm{~cm}$ (Tabela 1). À altura de $20 \mathrm{~cm}, 64,4 \%$ das plantas de algodoeiro rebrotaram com 7 DAR, enquanto apenas 12,9\% delas rebrotaram após a roçagem a $10 \mathrm{~cm}$ de altura. Essa desigualdade no padrão de rebrota foi observada até os 56 DAR, quando as plantas roçadas às alturas de $10 \mathrm{~cm}$ e $20 \mathrm{~cm}$ apresentaram, respectivamente, $45,0 \%$ e $100,0 \%$ de plantas com brotações (Tabela 1).

A partir dos 28 DAR, a cultivar FM 910 apresentou 100,0\% de plantas com brotações à altura de roçagem de $20 \mathrm{~cm}$. A partir dos 49 DAR, todas as cultivares apresentaram $100,0 \%$ de plantas com rebrota, no tratamento com roçagem a $20 \mathrm{~cm}$ de altura (Tabela 2). Já no tratamento com $10 \mathrm{~cm}$,

Tabela 1. Porcentagem de rebrota em plantas de algodoeiro roçadas em duas alturas, em três cultivares de algodoeiro (Jaboticabal, SP, 2011).

\begin{tabular}{|c|c|c|c|c|c|c|c|c|}
\hline \multirow{2}{*}{ Cultivar (C) } & \multicolumn{8}{|c|}{ Dias após a roçagem } \\
\hline & 7 & 14 & 21 & 28 & 35 & 42 & 49 & 56 \\
\hline FM 910 & $43,5 \pm 17,2 \mathrm{a}$ & $58,3 \pm 19,1 \mathrm{a}$ & $56,2 \pm 18,9 \mathrm{a}$ & $65,1 \pm 14,6 \mathrm{a}$ & $63,6 \pm 10,7 \mathrm{a}$ & $64,5 \pm 10,3 a$ & $68,3 \pm 6,8 \mathrm{a}$ & $75,8 \pm 4,1 \mathrm{a}$ \\
\hline NuOPAL & $44,6 \pm 16,9 a$ & $39,4 \pm 16,8 \mathrm{a}$ & $39,8 \pm 16,3 \mathrm{a}$ & $25,6 \pm 14,2 b$ & $53,3 \pm 12,4 \mathrm{a}$ & $55,9 \pm 12,4 a$ & $63,5 \pm 4,2 \mathrm{a}$ & $68,9 \pm 4,3 b$ \\
\hline DeltaOPAL & $27,9 \pm 18,0 \mathrm{a}$ & $28,6 \pm 18,6 \mathrm{a}$ & $30,4 \pm 17,5 \mathrm{a}$ & $38,4 \pm 16,9 \mathrm{ab}$ & $50,6 \pm 9,2 \mathrm{a}$ & $47,4 \pm 10,6 \mathrm{a}$ & $67,0 \pm 5,3 \mathrm{a}$ & $71,4 \pm 4,2 b$ \\
\hline $\mathrm{F}$ & $0,45^{\text {ns }}$ & $3,05^{\mathrm{ns}}$ & $2,60^{\mathrm{ns}}$ & $7,46^{* *}$ & $3,73^{*}$ & $2,63^{\text {ns }}$ & $2,87^{\mathrm{ns}}$ & $16,47 * *$ \\
\hline \multicolumn{9}{|c|}{ Altura (A) (cm) } \\
\hline 10 & $12,9 \pm 15,8 b$ & $14,7 \pm 15,7 b$ & $15,0 \pm 13,4 \mathrm{~b}$ & $23,9 \pm 14,2 b$ & $26,3 \pm 9,5 b$ & $30,4 \pm 10,4 b$ & $33,5 \pm 5,1 b$ & $45,0 \pm 3,8 \mathrm{~b}$ \\
\hline 20 & $64,4 \pm 13,8 \mathrm{a}$ & $69,5 \pm 13,2 \mathrm{a}$ & $69,2 \pm 15,9 \mathrm{a}$ & $62,2 \pm 12,0 \mathrm{a}$ & $85,4 \pm 6,1 \mathrm{a}$ & $81,4 \pm 11,7 \mathrm{a}$ & $100,0 \pm 6,0 \mathrm{a}$ & $100,0 \pm 2,1 \mathrm{a}$ \\
\hline $\mathrm{F}$ & $6,66^{*}$ & $20,15 * *$ & $20,51^{* *}$ & $16,45^{* *}$ & $128,99 * *$ & $55,28 * *$ & $2.228,90 * *$ & $5.436,74 * *$ \\
\hline $\mathrm{C} \times \mathrm{A}$ & $0,05^{\mathrm{ns}}$ & $1,87^{\mathrm{ns}}$ & $1,07^{\mathrm{ns}}$ & $3,45^{*}$ & $3,59 *$ & $3,77 *$ & $4,87^{*}$ & $16,48 * *$ \\
\hline CV (\%) & 68,88 & 57,22 & 54,33 & 41,88 & 17,54 & 23,58 & 4,25 & 2,11 \\
\hline
\end{tabular}

Médias seguidas pela mesma letra, na coluna, não diferem significativamente entre si, pelo teste Tukey, a $5 \%$. ns, ${ }^{*}$ e ${ }^{* *}$ : não significativo e significativo a $5 \%$ e a $1 \%$, respectivamente, pelo teste Tukey. 
Tabela 2. Valores da análise do desdobramento da interação entre cultivares de algodoeiro e altura de roçagem, para a porcentagem de plantas de algodoeiro com rebrota (Jaboticabal, SP, 2011).

\begin{tabular}{|c|c|c|c|c|c|c|}
\hline \multirow{3}{*}{ Cultivar } & \multicolumn{6}{|c|}{ Dias após a roçagem } \\
\hline & \multicolumn{2}{|c|}{28} & \multicolumn{2}{|c|}{35} & \multicolumn{2}{|r|}{42} \\
\hline & $10 \mathrm{~cm}$ & $20 \mathrm{~cm}$ & $10 \mathrm{~cm}$ & $20 \mathrm{~cm}$ & $10 \mathrm{~cm}$ & $20 \mathrm{~cm}$ \\
\hline FM 910 & $31,3 \pm 8,5 \mathrm{aB}$ & $100,0 \pm 0,0 \mathrm{aA}$ & $28,3 \pm 7,0 \mathrm{aB}$ & $100,0 \pm 0,0 \mathrm{aA}$ & $30,0 \pm 5,8 \mathrm{aB}$ & $100,0 \pm 0,0 \mathrm{aA}$ \\
\hline NuOPAL & $21,3 \pm 17,0 \mathrm{bA}$ & $30,0 \pm 26,9 \mathrm{cA}$ & $21,8 \pm 12,7 \mathrm{aB}$ & $84,8 \pm 17,4 \mathrm{aA}$ & $27,5 \pm 10,4 \mathrm{aB}$ & $84,3 \pm 30,0 \mathrm{abA}$ \\
\hline DeltaOPAL & $19,2 \pm 14,8 \mathrm{bB}$ & $57,7 \pm 36,9 \mathrm{bA}$ & $28,8 \pm 6,3 \mathrm{aB}$ & $72,5 \pm 20,9 \mathrm{aA}$ & $33,8 \pm 6,3 \mathrm{aB}$ & $61,0 \pm 34,2 \mathrm{bA}$ \\
\hline \multirow{3}{*}{ Cultivar } & \multicolumn{6}{|c|}{ Dias após a roçagem } \\
\hline & \multicolumn{3}{|c|}{49} & \multicolumn{3}{|c|}{56} \\
\hline & \multicolumn{2}{|c|}{$10 \mathrm{~cm}$} & $20 \mathrm{~cm}$ & \multirow{2}{*}{$\frac{10 \mathrm{~cm}}{52,5 \pm 2,9}$} & \multicolumn{2}{|r|}{$20 \mathrm{~cm}$} \\
\hline FM 910 & \multirow{2}{*}{\multicolumn{2}{|c|}{$\begin{array}{l}37,5 \pm 6,5 \mathrm{aB} \\
28,0 \pm 5,4 \mathrm{aB}\end{array}$}} & $100,0 \pm 0,0 \mathrm{aA}$ & \multirow{2}{*}{\multicolumn{2}{|c|}{$\begin{array}{l}52,5 \pm 2,9 \mathrm{aB} \\
38,8 \pm 2,5 \mathrm{cB}\end{array}$}} & $100,0 \pm 0,0 \mathrm{aA}$ \\
\hline NuOPAL & & & $0,0 \pm 0,0 \mathrm{aA}$ & & & \multirow{2}{*}{$\begin{array}{l}00,0 \pm 0,0 \mathrm{aA} \\
00,0 \pm 0,0 \mathrm{aA}\end{array}$} \\
\hline DeltaOPAL & \multicolumn{2}{|c|}{$35,0 \pm 4,1 \mathrm{aB}$} & $0,0 \pm 0,0 \mathrm{aA}$ & \multicolumn{2}{|c|}{$43,8 \pm 4,8 \mathrm{bB}$} & \\
\hline
\end{tabular}

Médias seguidas pela mesma letra não diferem estatisticamente entre si, pelo teste Tukey, a 5\%. Letras maiúsculas comparam médias na linha e minúsculas comparam médias na coluna, na mesma época de avaliação.

ficou evidente um padrão de rebrota inferior, mantendo porcentagens de plantas com rebrota abaixo de $50,0 \%$ ao longo das avaliações, exceto aos 56 DAR, quando alcançou valor máximo de $52,5 \%$, na cultivar FM 910 (Tabela 2).

De acordo com os resultados obtidos no presente trabalho, verificou-se que plantas de algodoeiro roçadas a $10 \mathrm{~cm}$ de altura apresentam, em geral, menos plantas rebrotadas, em relação a plantas roçadas a $20 \mathrm{~cm}$ de altura. Além da maior eficiência da operação realizada a $10 \mathrm{~cm}$, em relação à altura de $20 \mathrm{~cm}$, a roçagem em alturas mais baixas auxilia nos tratos culturais subsequentes (Lemon et al. 2003) e reduz os danos nos pneus de borracha, durante as semeaduras nos próximos plantios (Robertson 2002).

A avaliação do número de botões florais foi iniciada aos 56 DAR. As cultivares apresentaram valores de infestação baixos e sem diferenças significativas entre si. Apenas aos 77 DAR e 91 DAR, foram observados maiores valores para a DeltaOPAL, que diferiu significativamente da NuOPAL (Tabela 3).

Quanto à altura de roçagem, observa-se que, durante todo o período de avaliação, houve diferença significativa no número médio de botões florais presentes nas plantas roçadas a $10 \mathrm{~cm}$ e $20 \mathrm{~cm}$ de altura (Tabela 3). À altura de roçagem de $10 \mathrm{~cm}$, os primeiros botões florais foram emitidos aos 77 DAR e, aos 91 DAR, as plantas apresentaram, em média, 0,4 botões. Todavia, as plantas roçadas com $20 \mathrm{~cm}$, aos 63 DAR, apresentaram, em média, 1,0 botão por planta, atingindo 1,8 botões por planta, aos 91 DAR. Esse número é aproximadamente quatro vezes maior, em relação ao de plantas roçadas à altura de $10 \mathrm{~cm}$ (Tabela 3).

Tabela 3. Número de botões florais presentes em plantas roçadas em duas alturas e com rebrota, em três cultivares de algodoeiro (Jaboticabal, SP, 2011).

\begin{tabular}{lcccccc}
\hline \multirow{2}{*}{ Cultivar (C) } & \multicolumn{5}{c}{ Dias após a roçagem } \\
\cline { 2 - 7 } & 56 & 63 & 70 & 77 & 84 & 91 \\
\hline FM 910 & $0,1 \pm 0,4 \mathrm{a}$ & $0,4 \pm 0,7 \mathrm{a}$ & $0,4 \pm 0,3 \mathrm{a}$ & $0,4 \pm 0,7 \mathrm{~b}$ & $0,9 \pm 0,8 \mathrm{a}$ & $0,4 \pm 1,3 \mathrm{~b}$ \\
NuOPAL & $0,1 \pm 0,4 \mathrm{a}$ & $0,1 \pm 1,2 \mathrm{a}$ & $0,3 \pm 0,4 \mathrm{a}$ & $0,5 \pm 1,2 \mathrm{ab}$ & $0,8 \pm 1,4 \mathrm{a}$ & $1,4 \pm 1,3 \mathrm{a}$ \\
DeltaOPAL & $0,3 \pm 0,7 \mathrm{a}$ & $1,0 \pm 0,4 \mathrm{a}$ & $0,6 \pm 0,7 \mathrm{a}$ & $1,3 \pm 1,2 \mathrm{a}$ & $1,5 \pm 1,0 \mathrm{a}$ & $1,5 \pm 1,4 \mathrm{a}$ \\
\hline F & $0,42^{\text {ns }}$ & $2,30^{\text {ns }}$ & $0,60^{\text {ns }}$ & $4,22^{*}$ & $0,92^{\text {ns }}$ & $4,70^{*}$ \\
\hline Altura (A) (cm) & & & & & \\
10 & $0,0 \pm 0,0 \mathrm{~b}$ & $0,0 \pm 0,0 \mathrm{~b}$ & $0,0 \pm 0,0 \mathrm{~b}$ & $0,1 \pm 0,3 \mathrm{~b}$ & $0,4 \pm 0,8 \mathrm{~b}$ & $0,4 \pm 0,8 \mathrm{~b}$ \\
20 & $0,3 \pm 0,8 \mathrm{a}$ & $1,0 \pm 1,1 \mathrm{a}$ & $0,8 \pm 0,7 \mathrm{a}$ & $1,3 \pm 1,2 \mathrm{a}$ & $1,7 \pm 1,2 \mathrm{a}$ & $1,8 \pm 0,8 \mathrm{a}$ \\
\hline F & $6,67^{*}$ & $10,85^{* *}$ & $8,30^{*}$ & $27,93^{* *}$ & $6,39^{*}$ & $16,82^{* * *}$ \\
\hline C x A & $0,42^{\mathrm{ns}}$ & $2,30^{\mathrm{ns}}$ & $0,60^{\mathrm{ns}}$ & $6,16^{*}$ & $0,66^{\mathrm{ns}}$ & $5,99^{*}$ \\
\hline CV $(\%)$ & 20,63 & 34,21 & 35,84 & 24,14 & 41,64 & 27,41 \\
\hline
\end{tabular}

Médias seguidas pela mesma letra, na coluna, não diferem significativamente entre si, pelo teste Tukey, a $5 \%$. ${ }^{\text {ns }}, *$ e $* *$ : não significativo e significativo a $5 \%$ e a $1 \%$, respectivamente, pelo teste Tukey. 
Ainda em relação ao número de botões florais, houve interação significativa entre as cultivares e as alturas de roçagem somente aos 77 DAR e 91 DAR, quando as plantas roçadas à altura de $10 \mathrm{~cm}$ apresentaram valor máximo de 0,5 botão floral, nas plantas com rebrota. Por outro lado, à altura de $20 \mathrm{~cm}$, o número foi maior, atingindo 2,8 botões florais, na cultivar DeltaOPAL, aos 91 DAR (Tabela 4).

Os resultados obtidos à altura de roçagem de $20 \mathrm{~cm}$ indicam que essa altura deve ser evitada, pois, com esse tratamento, há maior capacidade de rebrota das cultivares e maior emissão de botões florais do que em plantas roçadas a $10 \mathrm{~cm}$ de altura. Essa situação se agrava, se levarmos em conta a preferência para alimentação do bicudo-do-algodoeiro por botões florais de dois dias de idade da cultivar NuOPAL e FM 910 e com sete dias de idade das cultivares DeltaOPAL, FMT 701 e FM 910 (Grigolli et al. 2012). Assim, a presença de botões florais em plantas de algodoeiro rebrotadas, em áreas cultivadas com DeltaOPAL, NuOPAL e FM 910, já é suficiente para atrair e manter a população de $A$. grandis na área de cultivo.
Os botões florais presentes nas plantas roçadas serviram como fonte de alimento para adultos de $A$. grandis e os danos foram observados a partir dos 63 DAR (Tabela 5). A cultivar DeltaOPAL foi a que apresentou maior porcentagem de botões florais danificados pelo bicudo-do-algodoeiro, ao longo de todas as avaliações, significativamente diferente das outras cultivares, nas três últimas datas de observação. As cultivares FM 910 e NuOPAL apresentaram porcentagens de botões florais atacados pelo bicudo-do-algodoeiro inferiores, ao longo das avaliações. Essa diferença da DeltaOPAL, em relação às outras cultivares, na mesma altura de roçagem, foi significativa nas três últimas datas de observação (Tabela 5).

As plantas que foram roçadas à altura de $20 \mathrm{~cm}$ apresentaram valores significativamente maiores de botões florais danificados pela alimentação do bicudo-do-algodoeiro, atingindo valores próximos a $50 \%$ de botões florais, a partir dos 77 DAR. Já as plantas roçadas a $10 \mathrm{~cm}$ atingiram valores máximos aos $91 \mathrm{DAR}$, sendo esses significativamente menores do que para os ataques ocorridos nas plantas roçadas a $20 \mathrm{~cm}$ (Tabela 5).

Tabela 4. Valores da análise do desdobramento da interação entre cultivares de algodoeiro e altura de roçagem, para o número de botões florais por planta de algodoeiro com rebrota (Jaboticabal, SP, 2011).

\begin{tabular}{lcccc}
\hline \multirow{2}{*}{ Cultivar } & \multicolumn{2}{c}{77 dias após a roçagem } & \multicolumn{2}{c}{ 91 dias após a roçagem } \\
\cline { 2 - 5 } & $10 \mathrm{~cm}$ & $20 \mathrm{~cm}$ & $10 \mathrm{~cm}$ & $20 \mathrm{~cm}$ \\
\hline FM 910 & $0,0 \pm 0,0 \mathrm{aA}$ & $0,8 \pm 1,0 \mathrm{bA}$ & $0,5 \pm 1,0 \mathrm{aA}$ & $0,3 \pm 0,5 \mathrm{bA}$ \\
NuOPAL & $0,3 \pm 0,5 \mathrm{aA}$ & $0,8 \pm 1,0 \mathrm{bA}$ & $0,5 \pm 1,0 \mathrm{aB}$ & $2,3 \pm 1,5 \mathrm{aA}$ \\
DeltaOPAL & $0,0 \pm 0,0 \mathrm{aB}$ & $2,5 \pm 1,0 \mathrm{aA}$ & $0,3 \pm 0,5 \mathrm{aB}$ & $2,8 \pm 1,0 \mathrm{aA}$ \\
\hline
\end{tabular}

Médias seguidas pela mesma letra não diferem estatisticamente entre si, pelo teste Tukey, a 5\%. Letras maiúsculas comparam médias na linha e minúsculas comparam médias na coluna, na mesma época de avaliação.

Tabela 5. Porcentagem de botões florais com orifícios de alimentação do bicudo-do-algodoeiro, em plantas roçadas em duas alturas e com rebrota, em três cultivares de algodoeiro (Jaboticabal, SP, 2011).

\begin{tabular}{|c|c|c|c|c|c|c|}
\hline \multirow{2}{*}{ Cultivar (C) } & \multicolumn{6}{|c|}{ Dias após a roçagem } \\
\hline & 56 & 63 & 70 & 77 & 84 & 91 \\
\hline FM 910 & $0,0 \pm 0,0$ & $6,3 \pm 17,7 a b$ & $18,8 \pm 37,2 \mathrm{a}$ & $18,8 \pm 37,2 b$ & $27,1 \pm 39,7 b$ & $18,8 \pm 37,2 b$ \\
\hline NuOPAL & $0,0 \pm 0,0$ & $0,0 \pm 0,0 \mathrm{~b}$ & $12,5 \pm 35,35 \mathrm{a}$ & $25,0 \pm 37,2 b$ & $14,6 \pm 27,2 b$ & $20,8 \pm 29,1 b$ \\
\hline DeltaOPAL & $0,0 \pm 0,0$ & $28,1 \pm 41,1 \mathrm{a}$ & $25,0 \pm 46,3 \mathrm{a}$ & $41,7 \pm 47,1 \mathrm{a}$ & $45,8 \pm 50,2 \mathrm{a}$ & $45,8 \pm 50,2 \mathrm{a}$ \\
\hline $\mathrm{F}$ & - & $4,25^{*}$ & $0,25^{\text {ns }}$ & $3,17 *$ & $4,76^{*}$ & $3,98^{*}$ \\
\hline \multicolumn{7}{|l|}{ Altura (A) $(\mathrm{cm})$} \\
\hline 10 & $0,0 \pm 0,0$ & $0,0 \pm 0,0 \mathrm{~b}$ & $0,0 \pm 0,0 \mathrm{~b}$ & $0,0 \pm 0,0 \mathrm{~b}$ & $4,2 \pm 14,4 b$ & $8,3 \pm 19,5 b$ \\
\hline 20 & $0,0 \pm 0,0$ & $22,9 \pm 35,6 \mathrm{a}$ & $27,5 \pm 48,3 \mathrm{a}$ & $56,9 \pm 45,4 \mathrm{a}$ & $54,7 \pm 43,2 \mathrm{a}$ & $48,8 \pm 45,7 \mathrm{a}$ \\
\hline $\mathrm{F}$ & - & $7,84^{*}$ & $6,65^{*}$ & $45,81 * *$ & $19,88^{* *}$ & $10,47 * *$ \\
\hline $\mathrm{C} \times \mathrm{A}$ & - & $4,25^{*}$ & $0,25^{\mathrm{ns}}$ & $2,17^{\mathrm{ns}}$ & $3,65 *$ & $4,40^{*}$ \\
\hline CV (\%) & - & 54,99 & 49,96 & 52,38 & 43,72 & 36,12 \\
\hline
\end{tabular}


Foi observada interação significativa das cultivares com as alturas de roçagem aos 63 DAR, $84 \mathrm{DAR}$ e $91 \mathrm{DAR}$, para o ataque do bicudo às flores (Tabela 5). À altura de roçagem de $10 \mathrm{~cm}$, a cultivar FM 910 foi a única que apresentou botões florais danificados pela alimentação de A. grandis, aos 84 DAR. Aos 91 DAR, a cultivar DeltaOPAL, à altura de roçagem de $20 \mathrm{~cm}$, apresentou a maior porcentagem de botões florais atacados por $A$. grandis, em relação à FM $910 \mathrm{e}$ NuOPAL (Tabela 6).

Nas avaliações quantificando o número de botões florais, verificou-se que a cultivar DeltaOPAL apresentou maior rapidez na emissão de botões florais, em plantas rebrotadas aos 77 DAR. A cultivar NuOPAL se igualou à essa variedade apenas aos 91 DAR, enquanto FM 910 apresentou o menor número de botões florais (Tabela 4). Esse resultado sugere que, na cultivar DeltaOPAL, a oferta de alimento para adultos de $A$. grandis foi antecipada e maior, em relação às outras cultivares, culminando com o maior número de botões florais com orifícios de alimentação observados.
Não foram observados orifícios de oviposição de $A$. grandis nos botões florais das plantas com rebrota, tanto nas plantas roçadas a $10 \mathrm{~cm}$ quanto a $20 \mathrm{~cm}$ de altura. Esse cenário pode estar relacionado com a época seca e de inverno, durante a condução do experimento, período de menor taxa de alimentação e de produção de ovos (Greenberg et al. 2005 e 2007b).

A presença de adultos de $A$. grandis nas plantas com rebrotas foi observada a partir dos 56 DAR. Em nenhuma das épocas de avaliação foi verificada diferença estatística entre as cultivares, para o número de adultos presentes nas plantas com rebrotas, porém, observou-se aumento da população de adultos da praga presentes nas plantas (Tabela 7).

As plantas com altura de roçada de $20 \mathrm{~cm}$ apresentaram maior número de adultos de $A$. grandis do que aquelas roçadas a $10 \mathrm{~cm}$, diferindo, significativamente, apenas aos 70 DAR, 84 DAR e 91 DAR. Isso, provavelmente, se deve à maior oferta alimentar e melhor condição de abrigo oferecidas pelas plantas com altura de roçada a $10 \mathrm{~cm}$, quando comparadas àquelas roçadas a $20 \mathrm{~cm}$.

Tabela 6. Valores da análise do desdobramento da interação entre cultivares de algodoeiro e altura de roçagem, para a porcentagem de botões florais com orifícios de alimentação do bicudo-do-algodoeiro (Jaboticabal, SP, 2011).

\begin{tabular}{lcccccc}
\hline \multirow{2}{*}{ Cultivar } & \multicolumn{2}{c}{63 dias após a roçagem } & \multicolumn{2}{c}{84 dias após a roçagem } & \multicolumn{2}{c}{91 dias após a roçagem } \\
\cline { 2 - 7 } & $10 \mathrm{~cm}$ & $20 \mathrm{~cm}$ & $10 \mathrm{~cm}$ & $20 \mathrm{~cm}$ & \multicolumn{1}{c}{$10 \mathrm{~cm}$} & $20 \mathrm{~cm}$ \\
\hline FM 910 & $0,0 \pm 0,0 \mathrm{aA}$ & $12,5 \pm 25,0 \mathrm{bA}$ & $12,5 \pm 25,0 \mathrm{aB}$ & $41,7 \pm 49,9 \mathrm{bA}$ & $12,5 \pm 25,0 \mathrm{aA}$ & $25,0 \pm 50,0 \mathrm{bA}$ \\
NuOPAL & $0,0 \pm 0,0 \mathrm{aA}$ & $0,0 \pm 0,0 \mathrm{bA}$ & $0,0 \pm 0,0 \mathrm{aB}$ & $29,2 \pm 34,1 \mathrm{cA}$ & $12,5 \pm 25,0 \mathrm{aA}$ & $29,2 \pm 34,1 \mathrm{bA}$ \\
DeltaOPAL & $0,0 \pm 0,0 \mathrm{aB}$ & $56,3 \pm 51,5 \mathrm{aA}$ & $0,0 \pm 0,0 \mathrm{aB}$ & $91,5 \pm 17,0 \mathrm{aA}$ & $0,0 \pm 0,0 \mathrm{aB}$ & $91,8 \pm 17,0 \mathrm{aA}$ \\
\hline
\end{tabular}

Médias seguidas pela mesma letra não diferem estatisticamente entre si, pelo teste Tukey, a 5\%. Letras maiúsculas comparam médias na linha e minúsculas comparam médias na coluna, na mesma época de avaliação.

Tabela 7. Número médio de adultos de $A$. grandis presentes nas plantas roçadas em duas alturas, com rebrota, nas cultivares de algodoeiro (Jaboticabal, SP, 2011).

\begin{tabular}{|c|c|c|c|c|c|c|}
\hline \multirow{2}{*}{ Cultivar (C) } & \multicolumn{6}{|c|}{ Dias após a roçagem } \\
\hline & 56 & 63 & 70 & 77 & 84 & 91 \\
\hline FM 910 & $0,1 \pm 0,4 \mathrm{a}$ & $0,3 \pm 0,5 \mathrm{a}$ & $0,3 \pm 0,5 \mathrm{a}$ & $0,3 \pm 0,7 \mathrm{a}$ & $0,5 \pm 0,5 \mathrm{a}$ & $0,4 \pm 0,5 \mathrm{a}$ \\
\hline NuOPAL & $0,1 \pm 0,0 \mathrm{a}$ & $0,3 \pm 0,5 \mathrm{a}$ & $0,1 \pm 0,4 \mathrm{a}$ & $0,4 \pm 0,5 \mathrm{a}$ & $0,4 \pm 0,5 \mathrm{a}$ & $0,5 \pm 0,5 \mathrm{a}$ \\
\hline DeltaOPAL & $0,3 \pm 0,5 \mathrm{a}$ & $0,1 \pm 0,4 \mathrm{a}$ & $0,3 \pm 0,5 \mathrm{a}$ & $0,5 \pm 0,5 \mathrm{a}$ & $0,6 \pm 0,5 \mathrm{a}$ & $0,6 \pm 0,7 \mathrm{a}$ \\
\hline $\mathrm{F}$ & $0,24^{\mathrm{ns}}$ & $0,43^{\text {ns }}$ & $0,24^{\mathrm{ns}}$ & $0,18^{\mathrm{ns}}$ & $0,47^{\mathrm{ns}}$ & $0,36^{\mathrm{ns}}$ \\
\hline \multicolumn{7}{|l|}{ Altura (A) $(\mathrm{cm})$} \\
\hline 10 & $0,1 \pm 0,3 \mathrm{a}$ & $0,1 \pm 0,3 \mathrm{a}$ & $0,0 \pm 0,0 \mathrm{~b}$ & $0,2 \pm 0,4 \mathrm{a}$ & $0,3 \pm 0,5 \mathrm{~b}$ & $0,2 \pm 0,4 b$ \\
\hline 20 & $0,2 \pm 0,4 \mathrm{a}$ & $0,3 \pm 0,5 \mathrm{a}$ & $0,4 \pm 0,5 \mathrm{a}$ & $0,6 \pm 0,7 \mathrm{a}$ & $0,8 \pm 0,5 \mathrm{a}$ & $0,8 \pm 0,7 \mathrm{a}$ \\
\hline $\mathrm{F}$ & $1,12^{\mathrm{ns}}$ & $3,86^{\mathrm{ns}}$ & $5,95^{*}$ & $4,1839^{\text {ns }}$ & $6,63 *$ & $9,96 * *$ \\
\hline $\mathrm{C} \times \mathrm{A}$ & $0,59^{\text {ns }}$ & $1,29^{\text {ns }}$ & $0,24^{\text {ns }}$ & $0,28^{\mathrm{ns}}$ & $0,47^{\text {ns }}$ & $1,14^{\mathrm{ns}}$ \\
\hline $\mathrm{CV}(\%)$ & 21,06 & 19,81 & 26,57 & 32,08 & 27,67 & 26,83 \\
\hline
\end{tabular}


Os resultados obtidos no presente trabalho indicam que a destruição da soqueira do algodão com a roçada com altura mais alta $(20 \mathrm{~cm})$ pode resultar em maior rebrote das plantas e maior emissão de botões florais, servindo de sítios de alimentação para o bicudo-do-algodoeiro e possibilitando sua permanência na área.

Dessa forma, a diferença no comportamento de rebrota das cultivares deve ser levado em conta no momento da destruição dos restos culturais, pois, se mal realizada essa operação, há grande potencial de rebrota e emissão de botões florais. Esses botões florais são utilizados como recurso alimentar por adultos de bicudo-do-algodoeiro, mantendo sua população em níveis elevados. Com isso, na safra subsequente, a população infestante tenderá a ser maior e os danos iniciais causados pela praga mais severos.

Os resultados obtidos à altura de roçagem de $20 \mathrm{~cm}$ indicam que essa altura deve ser evitada, pois há maior capacidade de rebrota das cultivares, maior emissão de botões florais e maior porcentagem de botões florais atacados pelo bicudo-do-algodoeiro do que em plantas roçadas a $10 \mathrm{~cm}$ de altura. Essa situação se agrava, se levarmos em conta a preferência para alimentação do bicudo-do-algodoeiro por botões florais de diferentes idades.

Grigolli et al. (2012) verificaram que o bicudo-do-algodoeiro prefere se alimentar de botões florais de dois dias de idade das cultivares NuOPAL e FM 910 e com sete dias de idade das cultivares DeltaOPAL, FMT 701 e FM 910. Assim, a presença de botões florais em plantas de algodoeiro rebrotadas, em áreas cultivadas com DeltaOPAL, NuOPAL e FM 910, já é o suficiente para atrair e manter a população do bicudo na área. Todavia, as diferenças observadas no presente trabalho envolvem, além da presença de botões florais, a capacidade de rebrota das cultivares, bem como o tempo necessário para emissão desses botões após a rebrota.

Não foram observados orifícios de oviposição de $A$. grandis nos botões florais das plantas rebrotadas, nas duas alturas de roçagem. Esse fato pode se explicar pelo período de entressafra da cultura, época seca e de inverno, quando o metabolismo dos adultos de $A$. grandis pode se encontrar menos ativo. O metabolismo reduzido, com prévio acúmulo de reservas, pode ser indicativo de preparação para a diapausa. Todavia, em regiões tropicais, o bicudo-do-algodoeiro não apresenta diapausa, e sim um estado de baixa atividade metabólica (Showler 2009). Segundo o mesmo autor, a diapausa não pode ser determinada por características consideradas isoladamente, ou em combinação com um ou dois fatores, por exemplo, o acúmulo de gorduras por alimentação e ausência de ovos, sendo que ambas as situações podem ser afetadas por déficits alimentares e condições climáticas, sem induzirem à diapausa.

Além disso, à medida que as plantas de algodão se desenvolvem na área, há aumento na dormência reprodutiva de fêmeas de $A$. grandis e, no período após a colheita da cultura, os adultos de bicudo-do-algodoeiro se encontram predominantemente nesse estado de dormência reprodutiva (Paula et al. 2013). Ainda segundo os mesmos autores, a fonte alimentar e as condições de campo, durante o desenvolvimento de insetos adultos, são decisivas na indução da dormência reprodutiva. Assim, as fontes de recursos alimentares existentes, como áreas de vegetação de Cerrado, têm papel primordial na sobrevivência de adultos de bicudo, principalmente no período da entressafra. Os sobreviventes do período de escassez alimentar da entressafra influenciarão a taxa de crescimento populacional, durante um novo ciclo do algodoeiro (Barbosa et al. 1983, Ribeiro et al. 2010).

A armadilha instalada para monitoramento, na área, indicou maior número de adultos capturados aos 14 DAR, com 4 adultos coletados (Figura 1). Ao longo das avaliações, ocorreu decréscimo na população adulta de $A$. grandis, na área experimental, atingindo zero adultos capturados na armadilha aos 84 DAR e 91 DAR. Esse fato era esperado, pois, com a emissão de botões florais aos 56 DAR, nas plantas roçadas a $20 \mathrm{~cm}$ acima do solo, esse inseto seria atraído para as plantas de algodão, para alimentação, em detrimento

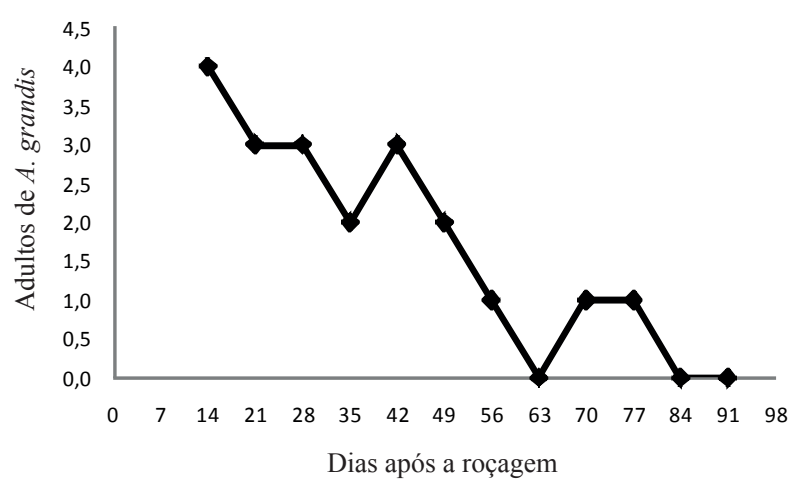

Figura 1. Número de adultos de $A$. grandis capturados em armadilha de feromônio, na área experimental (Jaboticabal, SP, 2011). 
da atração do feromônio sexual sintético (Grandlure) presente na armadilha.

Outros autores já observaram que os botões florais do algodoeiro exercem maior atração para os adultos do bicudo-do-algodoeiro do que os feromônios sexuais presentes nas armadilhas (Lloyd 1986, Rummel 1986). Além disso, Soares et al. (1994) associaram baixo número de indivíduos coletados nas armadilhas à preferência da praga por botões florais de algodoeiro.

O feromônio sexual de $A$. grandis é emitido pelos machos por meio de suas fezes e funciona como feromônio de agregação, durante o período de migração da praga (entressafra), enquanto, durante o período de frutificação das plantas de algodoeiro, Grandlure funciona como feromônio sexual de curta ação (USA 1981). Essa característica química dessa substância evidencia a preferência dos adultos de bicudo-do-algodoeiro por botões florais, em relação à armadilha instalada na área experimental.

Diante dos resultados obtidos, pode-se observar que a roçagem de plantas de algodoeiro a $10 \mathrm{~cm}$ de altura reduz sua capacidade de brotação, retarda a emissão de botões florais e, consequentemente, reduz a densidade populacional de adultos da praga na área, em relação a plantas roçadas a $20 \mathrm{~cm}$ de altura, as quais emitem brotações uma semana após a operação de roçagem, indicando que essa operação, nessa altura, não deve ser utilizada como estratégia de controle do bicudo.

A simples presença de brotações nos restos culturais decorrentes de plantas roçadas faz com que adultos de bicudo-do-algodoeiro permaneçam na área, entre os cultivos, alimentando-se de brotações ou de botões florais emitidos e aumentando o potencial biótico do inseto e seu poder destrutivo na safra subsequente.

\section{CONCLUSÕES}

1. Plantas roçadas a $10 \mathrm{~cm}$ de altura apresentam menor capacidade de brotação e de emissão de botões florais, enquanto plantas roçadas a $20 \mathrm{~cm}$ apresentam altos índices de rebrota, a partir dos sete dias após a roçagem.

2. As diferenças na capacidade de rebrota entre as cultivares ocorrem apenas aos 28 DAR e 56 DAR, para a cultivar FM 910, apresentando os maiores valores.

3. As cultivares DeltaOPAL e NuOPAL apresentam os maiores valores para número de botões florais por planta, sendo que, quanto à porcentagem de botões florais atacados, a cultivar DeltaOPAL apresenta os maiores valores aos 63 DAR, 77 DAR, 84 DAR e 91 DAR.

4. Não há diferenças para o número de adultos de A. grandis, entre as cultivares.

\section{AGRADECIMENTOS}

Ao Dr. José Carlos Barbosa, pelo suporte estatístico; à Coordenação de Aperfeiçoamento de Pessoal de Nível Superior (Capes) e ao Conselho Nacional de Desenvolvimento Científico e Tecnológico (CNPq), pela concessão de bolsas aos autores; e à Universidade Estadual Paulista (Unesp), pela infraestrutura fornecida.

\section{REFERÊNCIAS}

BARBOSA, J. C.; MALDONADO JÚNIOR, W. AgroEstat: sistemas para análises estatísticas de ensaios agronômicos. Versão 1.0. Jaboticabal: Ed. da Unesp, 2010.

BARBOSA, S. et al. Relatório sobre a ocorrência do bicudo-do-algodoeiro Anthonomus grandis Boheman, "Bollweevil", no Brasil e recomendações sobre sua erradicação. Campina Grande: Embrapa-CNPA, 1983.

BRASIL. Portaria $\mathrm{n}^{\circ} 75$, de 16 de junho de 1993. Diário Oficial da União, Brasília, DF, 16 jun. 1993a. Seção 2, p. 18.

BRASIL. Portaria $\mathrm{n}^{\circ}$ 77, de 23 de junho de 1993. Diário Oficial da União, Brasília, DF, 23 jun. 1993b. Seção 3, p. 72.

BRASIL. Portaria n ${ }^{\circ} 116$, de 16 de junho de 1994. Diário Oficial da União, Brasília, DF, 16 jun. 1994. Seção 3, p. 110.

CUADRADO, G. A. Anthonomus grandis Boheman (Coleoptera: Curculionidae) in central and southwest area of Misiones, Argentina: pollen as feeding source and their relationship with the physiological state in adult insects. Neotropical Entomology, Londrina, v. 31, n. 1 p. 121-132, 2002.

GREENBERG, S. M. et al. Reproductive potential of overwintering, F1, and F2 female boll weevils (Coleoptera: Curculionidae) in the Lower Rio Grande Valley of Texas. Environmental Entomology, College Park, v. 36, n. 2, p. 256-262, 2007a.

GREENBERG, S. M. et al. Chemical cotton stalk destruction for maintenance of host-free periods for the control of overwintering boll weevil in tropical and subtropical climates. Pest Management Science, Sussex, v. 63 , n. 4 , p. $372-380,2007$ b. 
GREENBERG, S. M. et al. Temperature-dependent development and reproduction of the boll weevil (Coleoptera: Curculionidae). Insect Science, Malden, v. 12, n. 6, p. 449-459, 2005.

GRIGOLLI, J. F. J. et al. Boll weevil feeding preference on squares at different ages and square shedding time of cotton cultivars. African Journal of Agricultural Research, Lagos, v. 7, n. 30, p. 4317-4323, 2012.

LEMON, R. et al. Cotton stalk destruction with herbicides. 2003. Disponível em: <http://sanangelo.tamu.edu/ agronomy/news/tr/stlkdest.html >. Acesso em: 19 set. 2011.

LLOYD, E. P. Ecologia do bicudo-do-algodoeiro. In: BARBOSA, S. et al. (Eds.). O Bicudo-do-algodoeiro. Brasília, DF: Embrapa-DDT, 1986. p. 135-144. (Documentos, 4).

PAULA, D. P. et al. Reproductive dormancy in bollweevil from populations of the midwest Brazil. Journal of Economic Entomology, Lanham, v. 106, n. 1, p. 86-96, 2013.

RAMALHO, F. S.; JESUS, F. M. M. Distribution of boll weevil (Anthonomus grandis) eggs within cotton squares. Tropical Agriculture, St. Augustine, v. 65, n. 3, p. 245248, 1988.

RIBEIRO, P. A. et al. Alternative food sources and overwintering feeding behavior of the boll weevil, Anthonomus grandis Boheman (Coleoptera, Curculionidae) under the tropical conditions of central Brazil. Neotropical Entomology, Londrina, v. 39, n. 1, p. 28-34, 2010.

ROBERTSON, B. Options for chemical stalk termination. 2002. Disponível em: <www.agriculture.org/cropsoilwtr/ cotton/comments/stalk termination.asp $>$. Acesso em: 21 set. 2011.

RUMMELL, D. R. Dinâmica populacional e níveis de dano. In: BARBOSA, S. et al. (Eds.). O Bicudo-doalgodoeiro. Brasília, DF: Embrapa-DDT, 1986. p. 201228. (Documentos, 4).

SHOWLER, A. T. Three boll weevil diapause myths in perspective. American Entomologist, Lanham, v. 55, n. 1, p. 40-48, 2009.

SOARES, J. J. et al. Efeito de práticas culturais de póscolheita sobre populações do bicudo-do-algodoeiro, Anthonomus grandis Boheman, 1843. Pesquisa Agropecuária Brasileira, Brasília, DF, v. 29, n. 3, p. 375379, 1994.

UNITED STATES OF AMERICA (USA). National Research Council. Cotton boll weevil: an evaluation of USDA programs: a report. Washington, DC: United States Department of Agriculture, 1981.

WALKER, J. K. Controle cultural do bicudo. In: BARBOSA, S. et al. (Eds.). O Bicudo-do-algodoeiro. Brasília, DF: Embrapa-DDT, 1986. p. 159-183. (Documentos, 4). 